\title{
Because people act, cities can be smart: Promoting social innovation in smart-city design-tools in the Mediterranean
}

\section{Carolina Mateo Cecilia, Miriam Navarro Escudero, Begoña Serrano Lanzarote, Vera Valero Escribano}

Instituto Valenciano de la Edificación. Valencia, Spain

E-mail: cmateo@five.es,mnavarro@five.es; bserrano@five.es; vvalero@five.es

\begin{abstract}
Smart city is an innovative paradigm tackling a range of emerging problems associated with urbanization, massively understood from a technologydriven approach. Much of the focus of the smart city movement to date - city authorities and other organizations deploying sensors, networks, decision support tools and data analytics to improve the efficiency and effectiveness of urban systems (like transport, utilities, etc.) - is only half the story. In occasions, citizens struggle with a top-down managing city system that should help public administrators, service providers and citizens, but reports instead on personal frustration. To avoid this, an attempt to promote social innovation processes to the smart city paradigm is now taking place. In this paper, we analyze reactions to a smart city design-tool for energy strategy plans'definition and implementation, in the three EU most populated Mediterranean countries (Spain, France, Italy). The research is based on the ACCENT study case. Interviews show common challenges with regard to ACCENT smartness, as the needs and dangers of sharing real energy consumption data of buildings, the low willingness of some energy suppliers to offer information, the userunfriendly interfaces for citizens, the lack of linkage among public bodies, the dispersion of data, the requirement of disseminating mechanisms to make citizens aware of the benefits of the energy renovation, or the inaccessibility to existing information on the state of buildings. These challenges resulting from ACCENT study give rise to three recommendations to foster social innovation in further Mediterranean smart city design-tools: co-responsibility, hand-in-hand co-creation and citizens' organizational empowerment.
\end{abstract}

Keywords: Social innovation, smart city, co-creation and coresponsibility, city management, ACCENT.

\section{Introduction}

The smart city concept is nowadays very extended in urban studies (Hollands, 2008; Vanolo, 2014). There are many definitions of smart cities. However, the most predominant one is focused on ICT as a technology driver and enabler, while less used but broader definitions include socioeconomic, governance and multi-stakeholder aspects such as the use of social participation to enhance sustainability, quality of life and urban welfare. Consequently, many studies showcase the smart city as a tech and sustainability frontrunner (Townsend, 2013), lacking figures on how can a smart city promote the social innovation that European Commission is looking for in Europe 2020 Strategy (EC, 2013).

Furthermore, it is well known the crucial importance of data collection when planning public policies (Genre, Flourentzos, \& Stockli, 2000). In order to achieve long term urban renovation processes, monitoring and managing smart decision-support tools are needed (Ascione, De Masi, de' Rossi, Fistola, \& Vanoli, 2012; Stylianidis, Karanikolas, \& Kaimaris, 2012; Hailu, 2012). The two most important 
aspects of these decision-support tools are (1) the manageability (Bhanot \& Jha, 2012) and (2) the integration of real data from different city stakeholders as service providers, citizens, policy makers and local authorities (Müller \& Siebenhüner, 2005).

Therefore, city management tools based on big data and technology driven processes are the most dominant in policy and scientific literature, based on the idea that policies with updated data are smarter since they are more effective, fiscally balanced and capable of attracting competitiveness, jobs, and human capital (Caragliu et al., 2011; Hancke et al,. 2013). Still, measuring success at city level is complicated as a consequence of the relative immaturity of smart city users and tools, and due to the difficulty of linking technology based solutions to particular socio-economic issues or social innovation processes.

This predominant vision places the smart cities in a neoliberal-trend public management of the city. However, some authors go further and do not assimilate the intelligent city as a neoliberal city (Harvey, 1989; Castells, 2000) or the uses of public spaces with neoliberal urban activities (Peck and Tickell, 2002). Initially, smart cities will be smart because their citizens have found new ways to craft, interlink and make sense of their own and each other's assets, data and other resources.

Smart cities are concerned with using data and coordinating local assets of all types to improve the lives of local inhabitants in terms of improved physical environments, mobility as well as community cohesion to tackle many of their own problems. But, which are the social patterns and trends behind a smart city? Does the technocratic smart city approach promote social polarization between low income areas and highincome areas? Or more specifically: Is social innovation a key aspect when designing smart cities design-tools? Indeed, the conclusions of the 2014 European Parliament study "Mapping Smart Cities in EU" underline that inclusion and participation are important targets for successful smart city design and management tools to avoid polarization between the urban elite and lowincome areas.

In order to avoid passed mistakes when promoting smart cities, in this paper we analyze social barriers of citizens, civil servants and service providers in a study case smart city design-tool called ACCENT: Accompany Cities in Energy Strategy. ACCENT focused mainly in building performance as buildings are responsible for approximately $40 \%$ of the primary energy consumption in Europe and often they are the largest energy consumer and $\mathrm{CO} 2$ emitting source in cities.

In this framework, municipalities have a vital need to reduce energy consumption in this sector through efficient policies and innovative solutions (Bloem, 2015). Hence, there is an urgent need to provide local authorities with tools to build up and update a realistic monitoring of the current situation (Ascione et al, 2012; Stylianidis et al, 2012). In order to achieve this goal, ACCENT is a new decision-support tool for local administrations developed under a pan-European project upheld by Climate KIC. ACCENT is a GIS web-based platform that supports local administrations to monitor public and private building energy performance and plan actions on the building stocks of the city. Therefore, ACCENT as a smart city design-tool, seeks to address public issues via ICT-based solutions on the basis of a multi-stakeholder, municipally based partnership.

In this research, we have focused on the main city-actor's reactions to ACCENT in Spain, France and Italy, the most populated EU countries in the Mediterranean area. The research questions launched are 1) if is there the danger of a one-size fits all, top-down view of urban city management with ACCENT and 2) which are the main barriers to achieve social innovation with ACCENT. The diverse needs of the inhabitants as individuals, households, neighborhoods, communities, organizations and businesses - that bring the city to life - are of such importance for this research. We end the paper formulating recommendations to promote social innovation in future smart city design-tools in EU Mediterranean countries. The hypothesis behind is that any adequate model for the smart city must also focus on the smartness of its citizens and encourage the social innovation processes. We believe that cities are, by definition, engines of diversity, so focusing solely on streamlining utilities, transport, construction and unseen government processes can be massively counter-productive. 


\section{Methodology}

In this study, we test ACCENT with local authorities and service providers in France, Italy and Spain. With this aim, five structured workshops were held involving local authorities and service providers from the different countries (Valero et al, 2016). The goal of these workshops was firstly, to identify the main challenges for the tool, and secondly, to assess how far ACCENT was promoting social innovation among the actors as visualized in Figure 1.

The starting point of the workshops were the results of the interviews made in a previous stage to make participants react to these results and to validate or invalidate them. In the second part of the workshops, a mock-up of the ACCENT tool was presented to participants in order to obtain their feedback about it. Once the mock-up of the ACCENT tool was refined and adapted, we went through an end-user oriented demonstration phase involving four different pilot cases: Paris, Valencia, Reggio Emilia and Ferrara.
This pilot phase aimed at achieving, on the one hand, a user-oriented tool for pilot cities, and on the other hand, a user-oriented tool for cities ecosystem: service providers and citizens. On a city-scale level, the work with cities consisted of five semi-structured meetings with cities' representatives. These meetings were focused on managing and guiding them to test the proof-of concept of the tool and analyse their suggestions of improvements regarding functionalities and ergonomics to iterate toward the final tool. In parallel, the needs of the cities ecosystem (service providers and citizens) were studied. Firstly, as shown in Figure 2, we developed a workshop with service providers in each pilot city to go further in their needs/expectations/barriers. With respect to citizens, the process consisted of interviews with citizen representatives (consumers, homemakers and other citizens' associations) in order to obtain information about which are the needs or expectations of citizens regarding energy saving and efficiency in their cities and buildings (For further information, see Mateo et al., 2017).

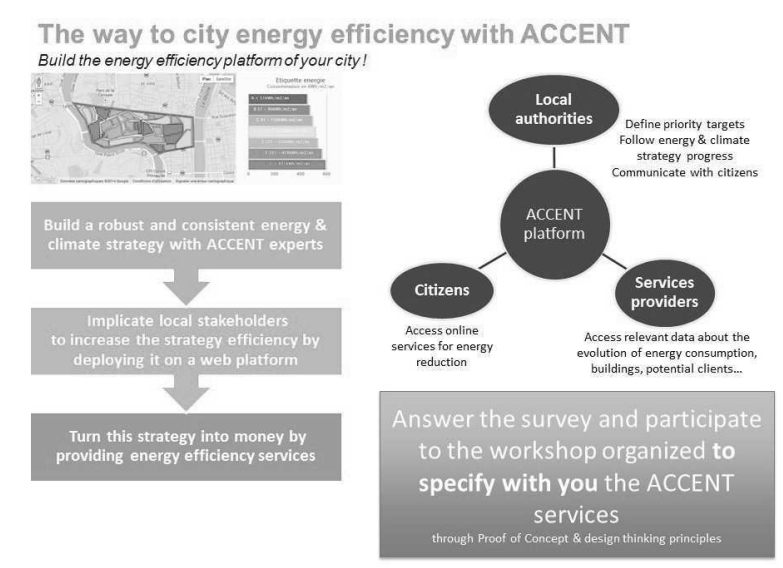

Figure 1.

Promoting social innovation through stakeholder participative workshops.



Figure 2.

Participative workshop with service providers. 
This participatory process allowed us firstly to determine societal challenges according to the different actors approached, and secondly to identify recommendations to foster social innovation while improving ACCENT smart city tool.

\section{Measurement and analysis}

Societal challenges identified during the development of ACCENT smart city designsupport tool

Hereafter societal challenges identified could be summed up in three: A/ Getting and using real energy data; $\mathrm{B} /$ Using decision-support tool for energy planning and $\mathrm{C} /$ Establishing links with other actors and learning from other similar experiences.

\section{Getting and using real energy data}

Energy consumption and $\mathrm{CO} 2$ emission reductions are both of key and growing importance on the political agenda. Local authorities need to have a realistic monitoring of the current situation; they have a strong need to understand the building stock energy consumption to be able to draw a strategy of energy efficiency, set targets and evaluate the impact of actions on energy consumption and $\mathrm{CO} 2$ emission reduction. Interviews undertaken with local administrators showed that normally municipalities get yearly real energy consumptions of the building stock at city scale. Furthermore, data are few years behind the current year of exploitation, depending on the type of data and the source. They also count on information regarding buildings and households provided by Statistics organisations (NSIs). Such organisations get data through population census and provide them to actors that evaluate the energy consumptions and $\mathrm{CO} 2$ emissions.

But most of the local administrations interviewed pointed out that to go further they need more detailed data at all levels. The scale of data needed depends on the actions to be carried out. Generally, lower scale is needed by technical actors, and upper scale information is targeting policy and strategic actors. On the one hand, the interviews have revealed that district and block scale is generally sufficient for municipalities because they are unable to target one precise building and they organize strategies at district level. But some municipalities would prefer information at building level, because they would have a more precise and reliable evaluation of the consumption. On the other hand, going down to the level of the dwelling could enable the public authorities to address issues of occupants, but for most actors this is considered as an intrusion into the privacy of citizens.

Furthermore, service suppliers have diverse needs concerning the scale of information needed. Interviews have revealed that they would like data at all types of scales, depending on their core business and their specific projects. Utilities' big investments would require data at regional level. For energy network companies, needs are at building and district levels. To develop district heating network, operators need to have at least the information at district level and preferably at building level too. For construction companies doing refurbishment works, data at building level is sufficient but they could need data at dwelling level. Some appliances companies would like the information at dwelling level or even more detailed inside the dwelling to have a precise analysis of the consumer behavior and offer them a dedicated service.

The third key actor worried with getting and using energy data were citizens. The results of the interviews conducted with representatives of citizens in the three countries (France, Spain and Italy) led us to common and similar conclusions. Interviewees agreed that the appropriate scale of data for citizens is dwelling/housing scale. This is the usual scale they manage energy data, and seem to be the more understandable for them. Furthermore, citizens are interested to monitor their energy consumption and get precise advices on energy saving measures and potential renovation works to improve the energy efficiency of their homes. In addition, it was also considered very interesting to provide them with information on energy consumption at city scale, as a necessary exercise of local government transparency, but also to include them in a collective effort, to allow citizens to understand how their actions influence city energy consumptions.

Apart from the needs identified, some 
barriers to respond to these needs came out regarding getting and using energy data for local administrators, service providers and citizens were:

-Reluctance of energy companies and citizens to share data. It seems that when companies are more integrated to the local level they are more willing to share data, but in countries like France, Italy, Spain, which have an energy system dominated by few major utilities, cooperation between national utilities, local governments and citizens is not easy and many issues have to be tackled.

-The confidentiality of the data is also a very important issue, especially information from the energy consumers for privacy reasons, but also from service providers for competitive reasons. Interviews reflected that generally stakeholders are willing to share the data and information they have if they get benefits in return. They are not willing to share them for free.

Using the decision-support tool for energy planning

In this case, we just identified barriers with local public administrators. Workshops and interviews with local administrators showed that defining energy strategies regarding the building stock starts with the knowledge and understanding of the current situation in terms of energy consumption and energy saving potential. It is difficult to have an intuitive knowledge of the building stock, even more for bigger cities. From this starting point, cities need a tool that allows them to design and evaluate different scenarios and alternatives based on a defined set of attributes, which can be used by city administrators, citizens and companies.

Barriers identified by local administrators were:

-Lack of financial capacity: most of the time energy systems or efficiency investments are driven by lower cost, which is a major source of problems for the future, due to a lack of consistency in long term results.

- Lack of city administrators with strong competences and tools. Some cities need to be supported by external consultants for these tasks. Additionally, citizens do not understand the information provided by these kind of tools.
Establishing links with other actors and learning from other similar experiences

Today, there is no meeting point between public authorities, service providers and the general public. Both local authorities and service providers are trying to bring services directly to citizens, but this has limited success across cities. This meeting point is strongly needed.

In addition, interviews and meetings hold with municipalities showed that they are really interested to learn from other cities' experiences. Sharing information with other cities implementing similar actions to the ones set out in their action plans can anticipate success or failures what provides margin to straighten up or given up actions, minimizing usefulness investment costs. Local administrations have the duty to orchestrate the development of the energy system on their territory. They do so by directing, more or less closely, the services and products supplied by providers, and by motivating the citizens to have virtuous behaviors regarding their energy consumption, which are not always effective.

Moreover, service providers wanted to communicate their activities and reach the market with their services or products. They firstly needed to know the energy strategy of their operation territory. This would help them elaborate clear and relevant services to address the action plan. But in this regard, we have found that sometimes there seem to be some discrepancies and contradictions, as e.g. Spanish service providers highlighted a gap between the local plan objectives and its implementation, what does not favour the planning of their core business strategies.

Finally, citizens need to have clear information about the challenges of their territory and their building regarding the energy consumption. Awareness raising and co-responsibility consciousness of environmental and economic issues are essential to success. They need to know what the proposed services are to make an educated choice among them. Consumers do not know where to go when they are looking for regulations, products and services for energy efficiency. They also demand information on service providers, about their reliability, quality, and performance. 
Barriers identified for local administrators, service providers and citizens were:

-Significant proportion of citizens without access to the internet or with difficulties to find the right information through this source. Other ways to address citizens are needed: face-to-face, school campaigns, neighbourhood associations, etc.

-There's a lack of communication between public administrations, at the same or different levels. SEAPs from municipalities at the same territory should be aligned to regional policies and vice-versa.

Recommendations to foster social innovation

According to the social barriers identified during the definition of ACCENT tool, we bring forward three specific recommendations to foster social innovation when designing a smart city decisionsupport tool. These are co-responsibility, handin-hand co-creation and citizens' organizational empowerment. The logical framework of the analysis is displayed in Table 1 .

Co-responsibility: People interviewed demanded data-sharing while keeping data confidential. This apparent oxymoron could be solved promoting co-responsibility in designing and using the smart platform. This could end with a win-win situation: having a space to codesign the city sharing responsibility of the decisions taken. All the open-source movements already act under these logics of governance. A smart city shouldn't result from a top-down design and management, in which some actors provide information and take responsibility while others suffer or benefit the consequences, and in which citizenship are considered passive. A smart city support-design tool should come up from an active society willing to improve the city management via transparent and open source governance tools, in which all actors assume responsibility.

Hand in hand co-creation: Most of the niches

Table 1.

Recommendations summary to foster social innovation according to the ACCENT societal challenges identified via the different actors approached.

\begin{abstract}
Societal challenges identified according to the different actors approached (local public administrators, service providers, citizens)

Getting and using real energy data.
\end{abstract}

Using decision-support tool for energy planning

Establishing links with other actors and learning from other similar experiences

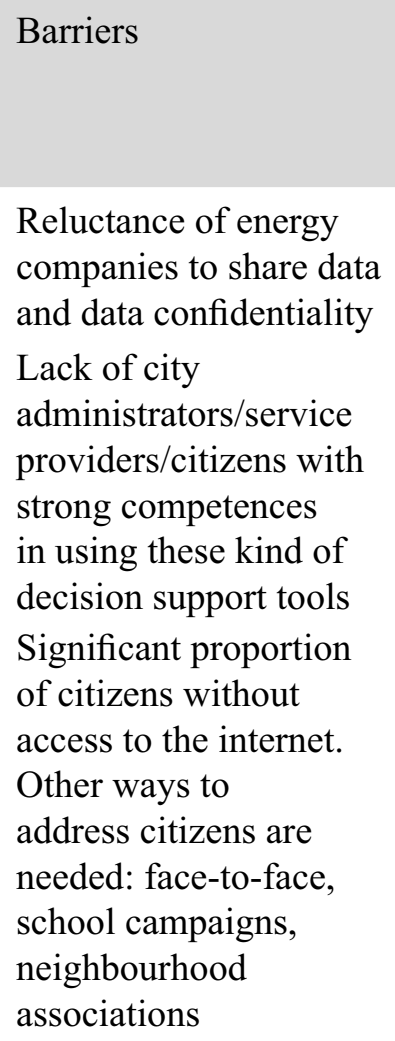

Hand-in-hand co-design

\section{Co-responsibility}
Citizens organizational empowerment


analyzed in this process complain about the unidirectionality of the municipalities when it comes to operating. The strategic objective of a smart city should be to develop better (energy/ other topics) decision support tools hand-inhand with community cohesion, in order to avoid the creation of tools not understandable by city administrators and/or citizens. Citizens interviewed demanded more capability to design the city that they live in. However, some city administrators see as a problem using participation methods to design the city as they have not the right training to manage these processes. That's why training is needed for both civil servants and citizens on participation and co-creation methods, in order to empower both sides of the urban development process and to promote new alliances and associations among citizens, civil servants or citizens-civil servants.

Citizens organizational empowerment: However, promoting hand in hand co-creation is not enough if these processes don't promote citizens' empowerment. For instance, without being asked, some citizens provided alternative ideation platforms to develop a better city, or competitions to take advantage of open public data to develop apps, useful data mash-ups or new services. Citizens empowerment could include ICT-enabled citizen participation open data strategies, crowdsourcing and co-creation platforms, but also alternative channels to the digitals one. One underlying theme should also be the resilient channels to promote city decisionmaking and enabling better feedback from citizens to civil servants. Additionally, awards and competitions could foster social innovation.

\section{Conclusion}

Today the identification of a smart city designtool with an intelligent city-council and with top-down management processes is overcome. In addition to the changes on governmental level speeches like UN Habitat III in this direction, we can affirm from the analyzed case that smart city users demand property and rights to the information that is generated in their cities, or voice in the decisions that affect the way in which their environment is transformed. The ACCENT study case highlights that citizens and city administrators need to be empowered through active participation to create a sense of ownership and commitment, so it is important to foster participative environments that facilitate and stimulate citizens, businesses and the public sector to contribute.

The engagement of all the city stakeholders in the city management is essential to promote smart cities. This collaborative approach allows service providers and citizens to play an effective role in planning and decision-making processes. However, this approach has also its limitations: the speediness of the ITC market and the rising needs of municipalities to reach their low carbon goals, has opened a very fast changing business niche, and it is not easy to actively promote social innovation when the business-driven processes are faster than local administrations.

\section{References}

Ascione, F., De Masi, R., de' Rossi, F., Fistola, R., \& Vanoli, G. (2012). Energy assessment in town planning: urban energy maps. (M. Pacetti , \& C. Brebbia, Eds.) The Sustainable City VII, 205-216.

Bhanot, J., \& Jha, V. (2012). Moving towards tangible decision making tools for policy makers: measuring and monitoring energy access provision. Energy Policy (47), 64-70.

Bloem H., Boguslawski R., Borzacchiello M. T., Piergiorgio C., Kona A., Martirano G., Maschio I. and Pignatelli F., "Location data for buildings related energy efficiency policies," European Commission - Joint Research Centre, Luxembourg, 2015

Castells, M. The Information Age: Economy, Society, and Culture. V. 1, The Rise of the Network Society, second edition. Oxford: Blackwell, 2000.

Caragliu, A., Bo, C. D., \& Nijkamp, P. (2011). Smart Cities in Europe. Journal of Urban Technology, 18(2), 65-82. http://doi.org/10.10 80/10630732.2011.601117

Datu, K y Lashermes, N (2014) What the Habitat III Agenda fails to consider. The Road to Habitat III. The Global Urbanist. Publicado el 22 de abril. Acceso: http://globalurbanist. com/2014/04/22/what-the-habitat-iii-agendafails-to-consider/print 
European Parliament (2014) Mapping Smart Cities in the EU. Available online: http:// www.europarl.europa.eu/RegData/etudes/ etudes/join/2014/507480/IPOL-ITRE ET(2014)507480 EN.pdf

European Commission (2013) Guide to social innovation. Available online: http://s3platform. jrc.ec.europa.eu/documents/20182/84453/ Guide to Social Innovation.pdf

Genre, J.-L., Flourentzos, F., \& Stockli, T. (2000). Building refurbishment: habitat upgrading. Energy and Buildings (31), 155-157.

Hancke, G., Carvalho e Silva, B., Hancke Jr, G. (2013). 'The Role of Advanced Sensing in Smart Cities'. Sensors, 13(1), 393-425; doi:10.3390/s130100393

Harvey, D. (1989) 'From managerialism to entrepreneurialism: the transformation in urban governance in late capitalism', Geografiska Annale, 71B(1), pp. 3-17.

Hollands, R. G. (2008). Will the real smart city please stand up? City, 12(3), 303-320. http:// doi.org/10.1080/13604810802479126

Mateo C., Valero V., Navarro M., "Do municipalities have the right tools to become zero carbon emissions cities? Accent, a Pan-European decision-support tool to take refurbishment decisions at city scale based on buildings energy performance" in Green Energy and Technology Springer book, Ed by Roberto Alvarez (2017)

Müller, M., \& Siebenhüner, B. (2005). Policy instruments for sustainability-oriented organizational learning. Business Strategy and the Environment, 233.

Peck, J., \& Tickell, A. (2002). Neoliberalizing Space. Antipode, 34(3), 380-404. http://doi. org/10.1111/1467-8330.00247

Stylianidis E., Karanikolas N. and Kaimaris D., "A Gis for urban sustainability indicators in spatial planning," International Journal of Sustainable Development and Planning, vol. 7, no. 1, pp. 1-13, 2012.

Townsend, A. M. (2013). Smart Cities: Big Data, Civic Hackers, and the Quest for a New Utopia (1 edition). New York: W. W. Norton \& Company.

Valero V., Navarro M., Mateo C. \& TesseronStevelinck S. (2016) "ACCENT: a pan-European co-created tool to take refurbishment decisions at a city scale based on buildings' energy performance" at WIT Transactions Eleventh International Conference on Urban Regeneration and Sustainability The Sustainable City (Congress Book) XIEd WIT Press, UK ISBN: 978-178466-103-8 eISBN: 978-1-78466-104-5 PP 65-79.

Vanolo, A. (2014). Smartmentality: The Smart City as Disciplinary Strategy. Urban Studies, 51(5), 883-898. http://doi. org/10.1177/0042098013494427 